\title{
AXIAL FORCE AND DEFORMATION OF A RESTRAINED STEEL BEAM IN FIRE Description and validation of a simplified analytical procedure
}

\author{
Naveed Iqbal ${ }^{1, *}$, Tim Heistermann ${ }^{1}$, Milan Veljkovic ${ }^{1}$, Fernanda Lopes ${ }^{2}$, \\ Aldina Santiago ${ }^{2}$ and Luis Simões da Silva ${ }^{2}$ \\ ${ }^{1}$ Luleå University of Technology, Division of Structural and Construction Engineering, Luleå, Sweden \\ ${ }^{2}$ University of Coimbra, Department of Civil Engineering, Coimbra, Portugal \\ *(Corresponding author: E-mail: naveed.iqbal@ltu.se) \\ Received: 17 February 2015; Revised: 7 May 2015; Accepted: 28 July 2015
}

\begin{abstract}
Structural fire design is exceedingly adopting the performance based approach. There are evident advantages of this approach compared to the prescriptive methods from codes. An analytical procedure, based on the real performance, must accurately predict the beam behaviour in fire. The study presented here proposes one such simplified analytical procedure aim to predict the real behaviour of a restrained steel beam. The proposed analytical procedure is validated through FE Analysis using FE models validated through test results. The study also attempts to establish the importance of using semi-rigid connection strength with respect to accurately predicting the behaviour of the restrained beam at catenary stage.
\end{abstract}

Keywords: Structural fire design, performance based design, Abaqus, fire tests, simplified design procedure, catenary action

DOI: $10.18057 / I J A S C .2016 .12 .2 .6$

\section{INTRODUCTION}

The prescriptive design approach in fire from design codes requires each structural component to fulfil their design requirement in isolation. This approach overlooks the interaction between different structural components in fire situations that might be unfavourable in some and favourable in other cases. Advanced numerical modelling tools have enabled the application of the performance base approach for design of structures in fire. Based on sound engineering principles and calculations, complex structural systems such as composite structures can be analysed with such tools. Contrary to the prescriptive approach, performance based design is more complex and its application is relatively case specific.

The World Trade Centre (WTC) towers collapses have shown how damaging the interaction between different structural members can be in fire [1]. Other examples such as the full scale building tests conducted by the Building Research Establishment (BRE) at Cardington have led to useful data regarding redundant structural systems in fire [2].

The focus of this study is the analysis of the behaviour of a restrained steel beam in fire. The restrained behaviour of a steel beam in fire has also been previously studied by other researchers. Liu et al tested a sub-frame in fire using two different types of connections: flush end plate and web-cleat connections [3]. Yin and Wang investigated the effect of axial and rotational stiffness on a restrained steel beam in a sub-frame exposed to fire [4]. They further developed an analytical procedure to describe the behaviour of a restrained steel beam in fire. The procedure was validated using FE modelling [5], [6]. Li and Guo [7] also included the cooling phase in their study to assess the tensile forces produced as a result. Santiago et al [8] focused on the role of end restraints on a steel beam in a sub-frame exposed to natural fire conditions (heating and cooling phases). Gillie 
used a benchmark study to demonstrate the complexity of the behaviour of a restrained steel beam at elevated temperatures compared to the assumption of an isolated member in standard fire tests [9].

\section{ANALYTICAL PROCEDURE}

\section{$2.1 \quad$ Introduction}

Figure 1 shows the axial force-vs-temperature curve of the beam. Under fire exposure the beam is initially compressed due restrained expansion. Later as the beam is heated further, the material strength and stiffness is considerable reduced causing the beam to deflect and release the initial compression and transition into the tensile phase. The beam at this stage behaves like a catenary resisting part of the applied load. An analytical procedure should enable the designer to predict the level of the axial force and deflection of the beam during fire exposure.

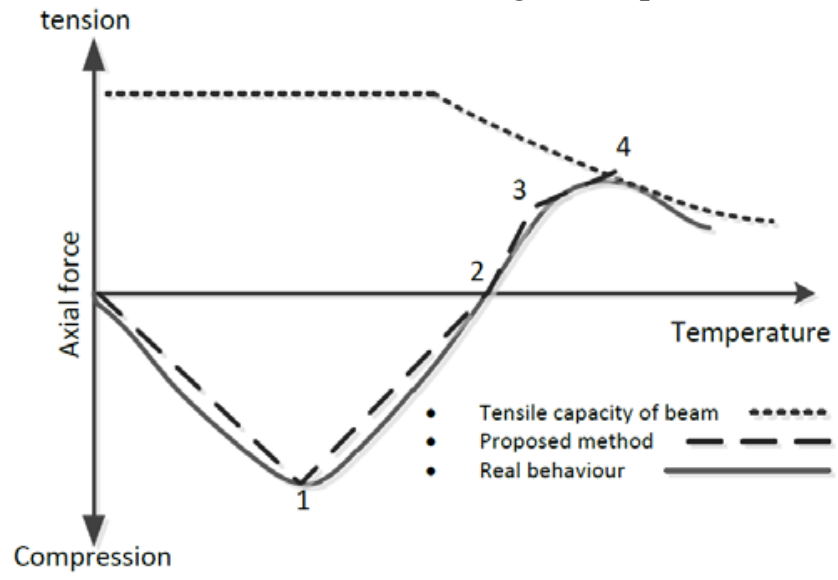

Figure 1. General Variation of the Axial Force in a Restrained Steel Beam in Fire

The procedure presented here is based on a concept presented by Wang et al. [10]. The original method proposes calculating three transition points on the axial force-vs-temperature curve. These points are the maximum compressive force (1), zero axial force (2) and maximum tensile force (4) (Figure 1). These points are joined together by straight lines to get the approximate axial force-vs-temperature curve.

\subsection{Proposed Novel Approach}

To obtain a better approximation of the curve, the proposed procedure has four transition points instead, which are calculated and then joined together forming the broken line in Figure 1. This approach provides a comparatively better approximation of the axial force vs temperature relationship of the beam due to its extra transition point 3 and consideration of the residual bending moment resistance from point 2 to point 3 . The details of the procedure are described as follows.

\subsubsection{Maximum compressive force}

The first transition point (1) on the axial force vs. temperature curve of a restrained steel beam is the maximum compressive force developed due to the beams' restrained thermal expansion. The maximum compressive force is determined by considering its interaction to the bending moment produced by the imposed loading on the beam. The interaction equation from Eurocode 3 part 1-2 has been considered in the analytical procedure presented here [11]. Increasing temperature will reduce the modulus of elasticity and yield strength of steel, which implies that an iterative 
procedure will be adopted to calculate the maximum compressive force and the temperature at which it will be achieved. Figure 2 shows a schematic diagram of the procedure used for this purpose.

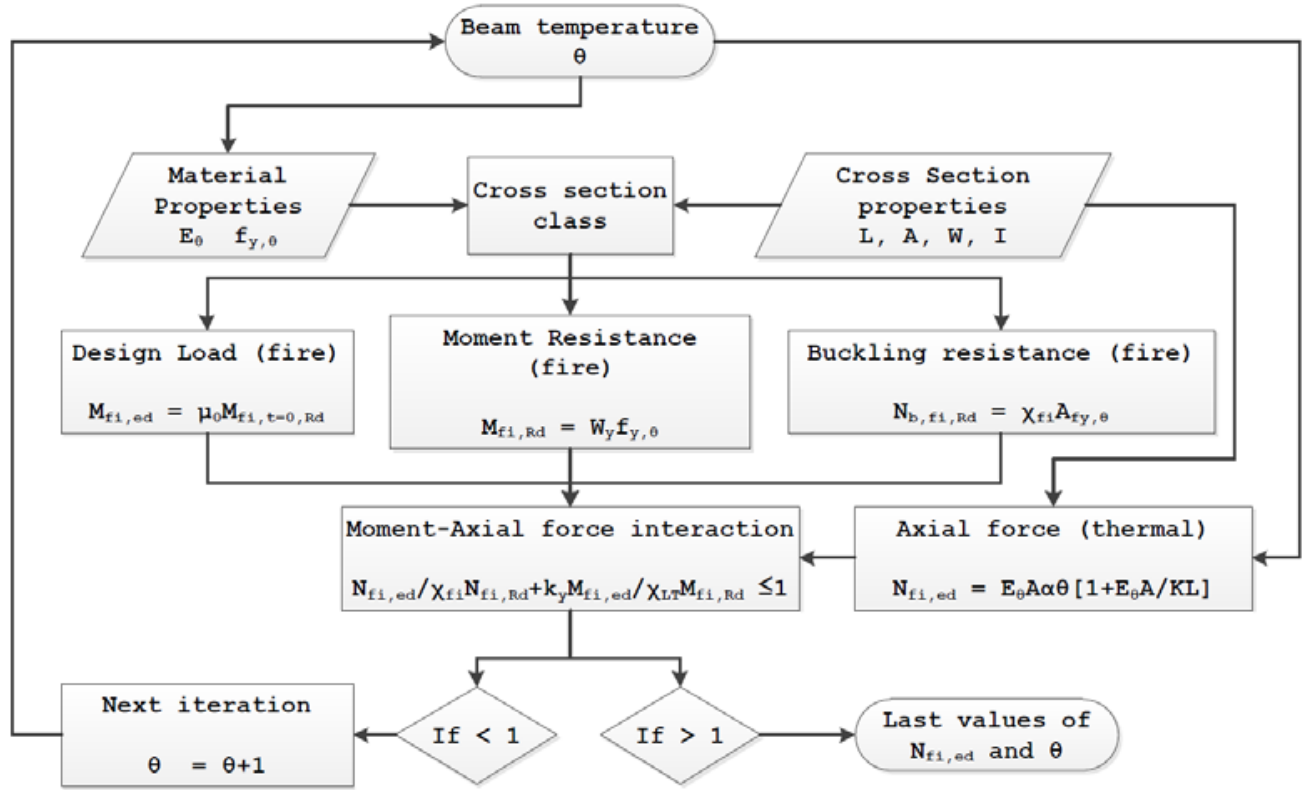

Figure 2. Schematic Diagram of the Calculation of Maximum Compressive Force

The assumptions considered in the calculation shown in Figure 2 are as follows:

- Axial force in the beam is calculated from the equation taken from Usmani et al. [12]:

$N_{f i, E d}=E_{\theta} A \alpha \Delta T\left[1+\frac{E_{\theta} A}{K L}\right]$

- The stiffness ' $\mathrm{K}$ ' in Eq. 2.1 above is the stiffness of the supporting.

- The deflection of the beam is assumed to be elastic during this initial phase.

- The beam is assumed to be restrained from lateral torsional buckling.

\subsubsection{Zero axial force}

The first phase of the axial force-temperature curve concludes at point (1). As the temperature increases, further the compressive force in the beam reduces until it becomes zero, i.e. point (2) on the curve shown in Figure 1. From equilibrium, the imposed load is resisted only through flexural bending resistance up to point (2). At this point, the bending moment resistance of the beam is exactly equal to the bending moment from the imposed loading.

The temperature at point (2) is determined from the yield strength of the steel using condition of equality between the moment resistance and the imposed loads as shown in Figure 3. 


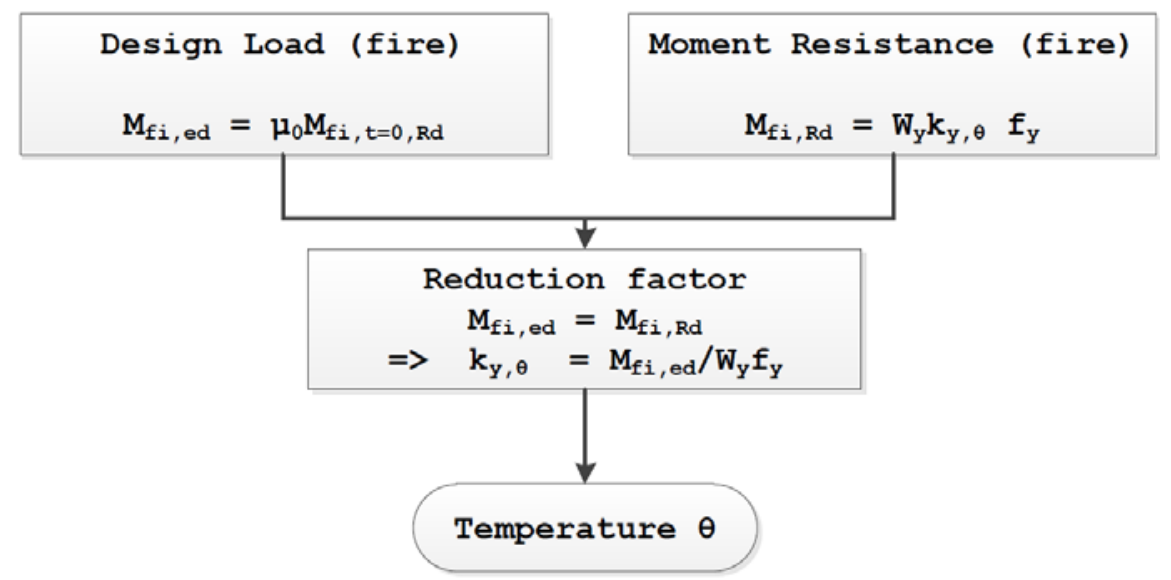

Figure 3. Limiting Temperature for the Bending Moment Resistance of the Beam

The calculation shown in Figure 3 is based on following assumptions:

- The bending moment resistance of the beam is directly proportional to the yield strength of the steel material, disregarding lateral torsional instability.

- The beam is assumed to be simply supported.

The temperature at point (2) corresponds to the conventional limiting temperature of a steel beam according to Eurocode 3 part 1-2.

If a semi-rigid connection is considered, then its strength and stiffness must be used. These will vary with increasing temperature, which must be taken into account. The Initial stiffness and strength of the connection are directly proportional to the modulus reduction factor $k_{E, \theta}$ and the yield strength reduction factor $k_{\mathrm{y}, \theta}$, respectively, according to EN 1993-1-2 [11].

A modified procedure is thus used to calculate point (2), described in Figure 5. This procedure would also introduce the connection temperature into the calculation. Generally, the beam temperature at midspan is higher than the connection temperature due to the concentration of mass at the connection. An equation from Annex D of EN 1993-1-2 has been used here to determine the connection temperature shown below as Eq. 2.2 [11].

$\theta_{\text {conn }}=0.88 \cdot \theta_{\text {beam }}[1-0.3(h / D)]$

The temperature of an unprotected steel beam subjected to a standard fire (ISO 834) is determined using Eq. 2.3 below, from EN 1993-1-2 [11].

$\Delta \theta_{\text {beam }}=k_{s h} \frac{A_{m} / V}{c_{a} \rho_{a}} \dot{h}_{\text {net }} \Delta t$

The steel beam with an IPE 300 profile and the connection temperature with increasing time, when uniformly exposed to a standard ISO 834 fire, is shown in Figure 4. 


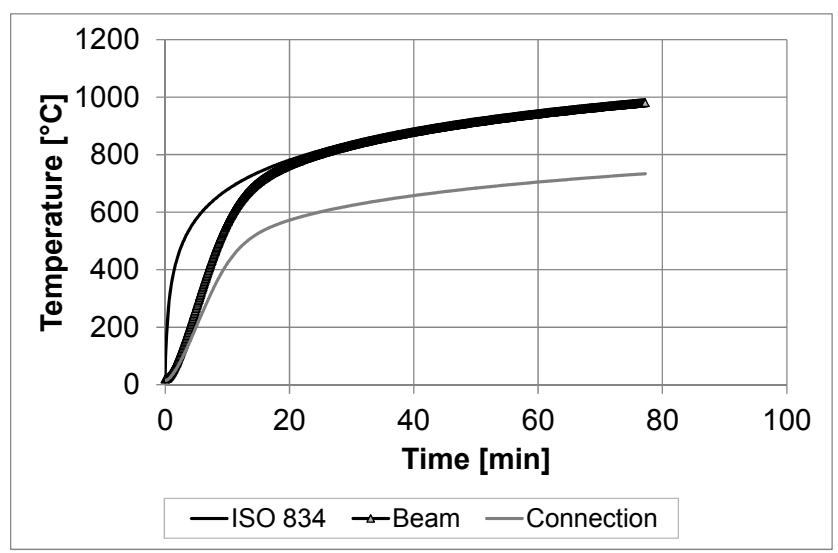

Figure 4. Temperature-vs-time Curves

As a first approximation, the reduction factor $k_{\mathrm{y}, \mathrm{conn}}$ is calculated using the beam temperature at point (2) according to Figure 3. This value of $k_{y, c o n n}$ is the starting value in the loop shown in Figure 5. Once the loop gives repeating values of $k_{\mathrm{y}, \text { conn, }}$ it is terminated and the last value of beam temperature in the loop is taken as point (2) on the curve.

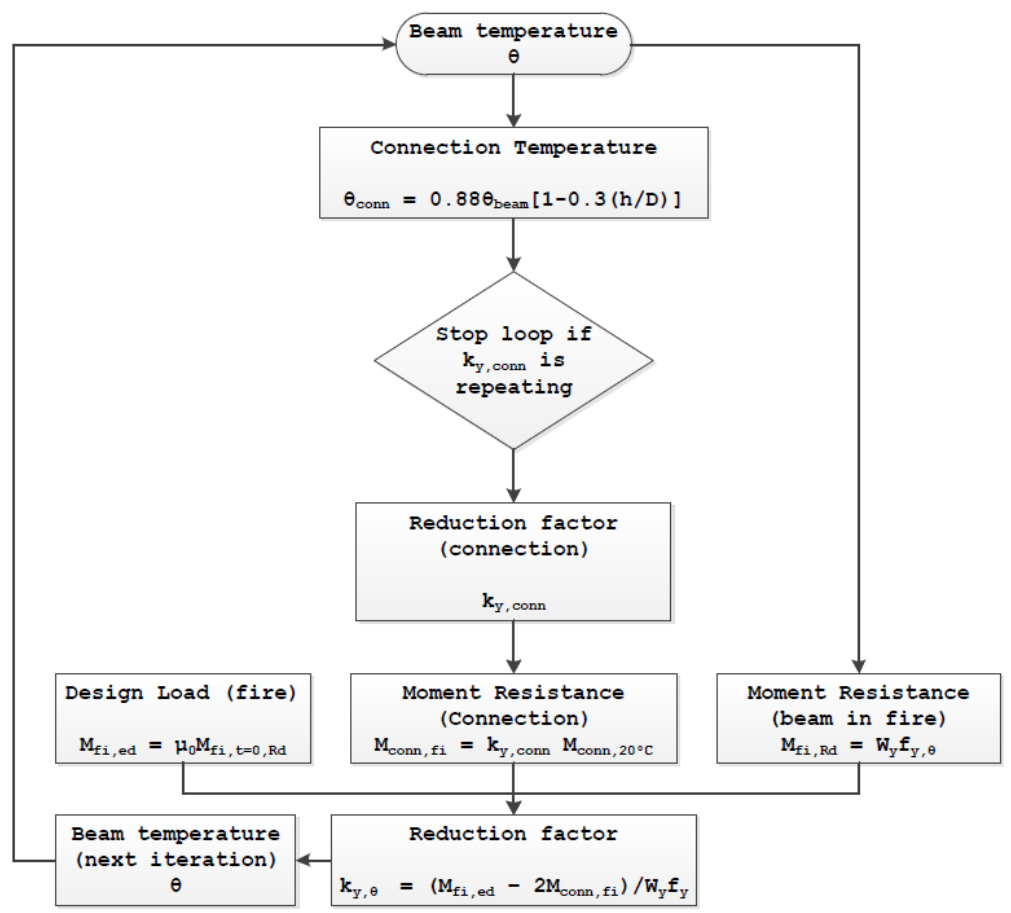

Figure 5. Calculation of the Reduction Factor for the Connection

The midspan deflection of the beam at this point is calculated using the deflection profile proposed by Dwaikat and Kodur, described in Figure 6 [13].

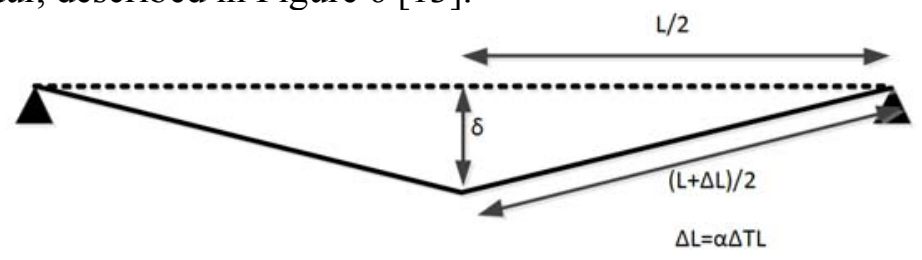

Figure 6. Deflection Profile of the Beam during Catenary Phase 


\subsubsection{Maximum tensile force}

As the temperature increases beyond point (2) calculated above, it is evident that the bending moment resistance of the beam is insufficient to resist the imposed loading. A simply supported beam would undergo runaway deflection at this point. However, a restrained beam would develop an additional resistance through the tensile axial force in the beam resisted at the supports through a catenary action. The bending moment resistance of the beam will progressively decrease with corresponding increase in catenary action as the temperature increases. The limit to the catenary action in the beam is imposed by the beams tensile capacity.

The midspan deflection of the beam in the catenary phase is also calculated using Eq. 2.4 based on profile in Figure 6.

$\delta=\sqrt{\left[\frac{L+\alpha \Delta T L}{2}\right]^{2}-\left[\frac{L}{2}\right]^{2}}$

The catenary phase can be divided into two distinct phases, i.e. without interaction between catenary force and residual bending moment and with interaction between them.

The boundary between these two phases is at point (3) in Figure 1, determined by calculating the axial force and bending moment resistance for each temperature increment beyond point (2) on the curve. The criteria for no interaction between the axial force and bending moment is checked at each increment and continued if satisfied. The last increment that satisfies this condition is the point from which onwards the catenary force will interact with the bending moment resistance. This calculation procedure can be easily understood through the schematic diagram of Figure 7.

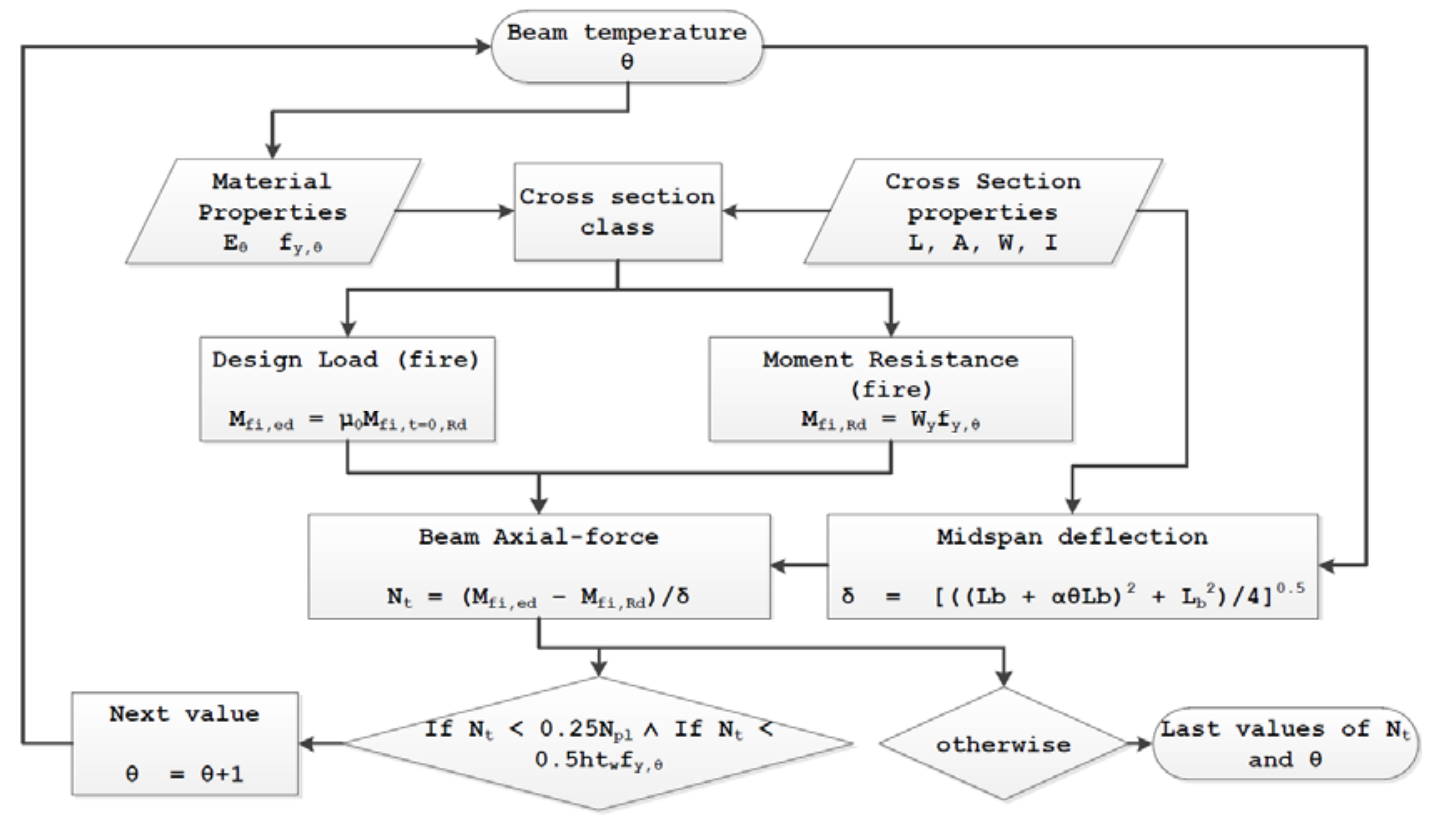

Figure 7: Schematic Diagram of the Calculation of Temperature during the Catenary Phase up to which there is no Interaction between the Axial Force and the Bending Moment Resistance 
Last point (4) on the curve is determined by assuming that the bending moment resistance is zero and catenary action is solely responsible for resisting the imposed load. The catenary force is equal to the tensile capacity of the beam at this point; beyond this point the beam undergoes runaway deflection.

\section{FINITE ELEMENT MODEL}

The hand calculation procedure has been validated using FE Analysis, in Abaqus [14]. The FE models were validated against test results on sub-frames at elevated temperatures discussed below.

\subsection{Sub-frame Tests}

The sub-frame tests were performed at the University of Coimbra. This was done within a European project COMPFIRE [15]. Under the COMPFIRE project, a novel connection consisting of a reverse channel between steel beam and Concrete Filled Tubular (CFT) columns was studied at elevated temperatures. The aim of this project was to demonstrate the large rotational capacity of this connection type at elevated temperatures compared to other types of connections [15].

Full scale tests were carried out on sub-frames consisting of an IPE 300 profile beam supported at each end by a CFT column through reverse channel connections. The columns are $3525 \mathrm{~mm}$ tall and the beam has a $5000 \mathrm{~mm}$ long span shown in Figure 8 [16]. Other details of test specimens are given in Table 1 below.

Table 1. List of Sub-frame Models at Elevated Temperature

\begin{tabular}{|c|c|c|c|}
\hline $\begin{array}{l}\text { Test } \\
n^{\circ}\end{array}$ & Temperature curve & Column section & Reverse channel \\
\hline 1. & Heating $1+$ cooling & SHS 250x10 & U 200x90x10 \\
\hline 2. & Heating $2+$ cooling & SHS 250x10 & U 200x90x10 \\
\hline 3. & Heating $1+$ cooling & SHS 250x 10 & U 200x90x8 \\
\hline 4. & Heating $1+$ cooling & SHS $250 \times 10$ & U $200 \times 90 \times 12$ \\
\hline
\end{tabular}

In each case, the beam has a utilization factor of 0.2 , i.e. $47 \mathrm{kN}$ constant load. The connections, webs and the bottom flanges are heated using flexible ceramic heating pads. The top flange was not directly heated in order to simulate the heat sink effect of the concrete slab. The column was also not heated directly [16].

The measurements made during the tests include the midspan deflection, reaction forces at the column ends and temperatures along the beam span and connections. 


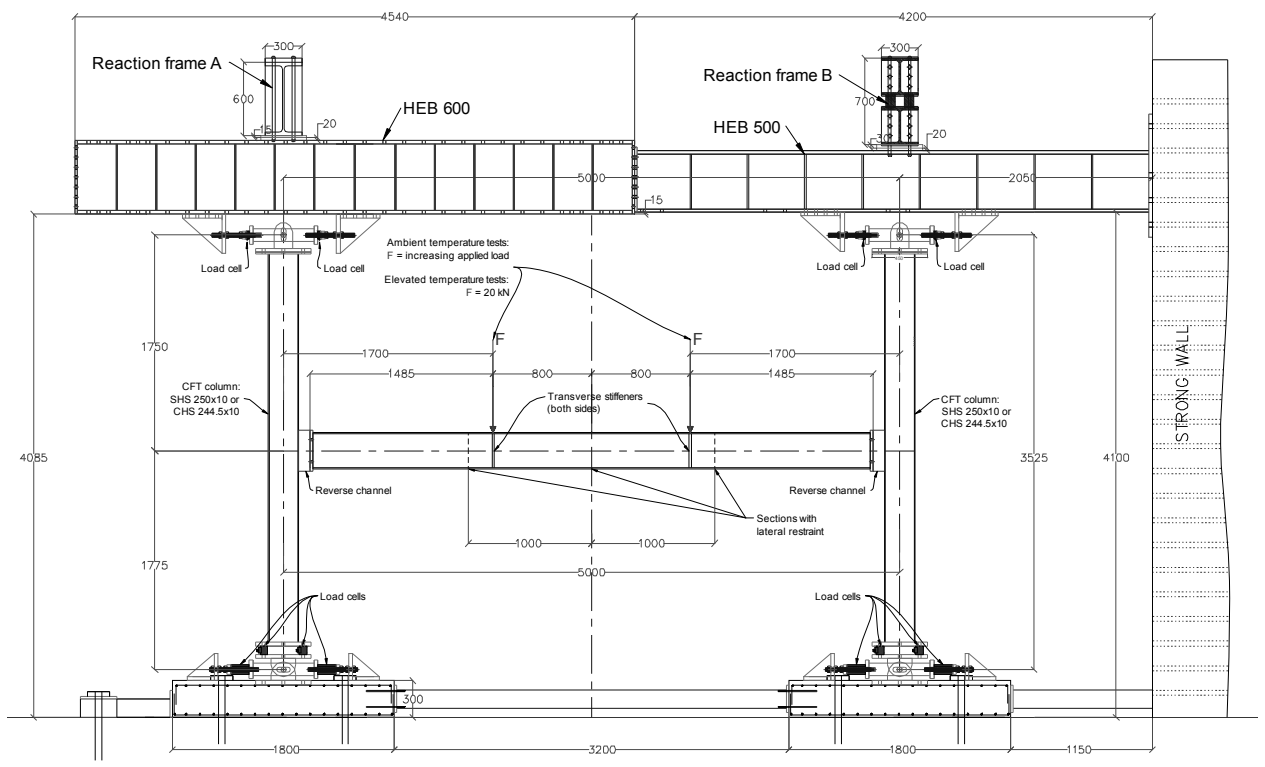

Figure 8. Experimental Setup of the Sub-frame Tests [16]

The lateral torsional instability is prevented by restraining lateral translation along the span of the beam.

All steel components are made of Steel S355 except the end-plates, which are of S275. The concrete in CFT column is grade C30 37 . The bolts in connection are M24 grade 10.9 [16].

\subsection{Connection Strength}

The reverse channel connection is expected to behave as a semi-rigid connection. There are presently no rules in Eurocode 3 for calculation of the strength and initial stiffness of reverse channel connections, therefore numerical procedures have been used for their calculation using FE Models of the connections shown in Figure 9.

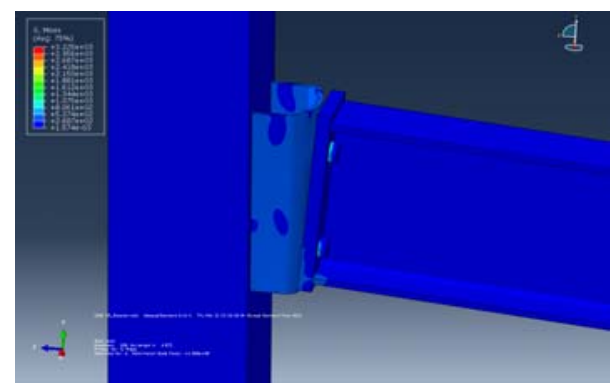

Mises Stress distribution

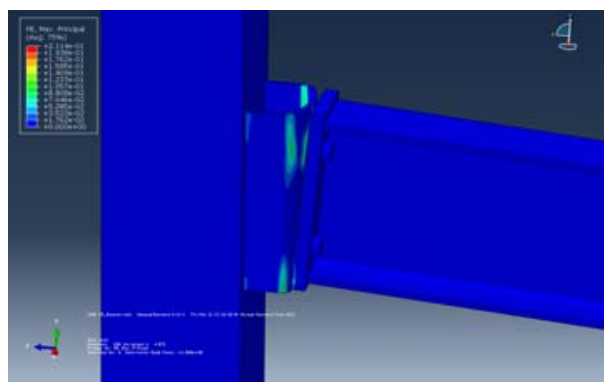

Principal plastic strain distribution

Figure 9. Deformed Shape of a Reverse Channel Connection

The moment-vs-rotation diagram is plotted for the connection by measuring the rotation of the beam near the connection. These plots are shown below in Figure 10. 


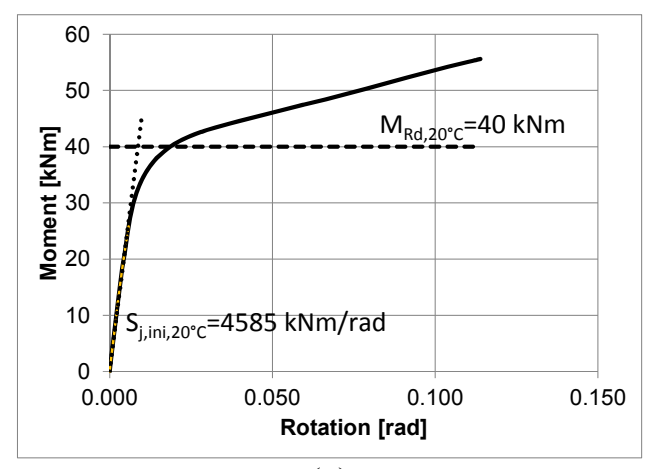

(a)

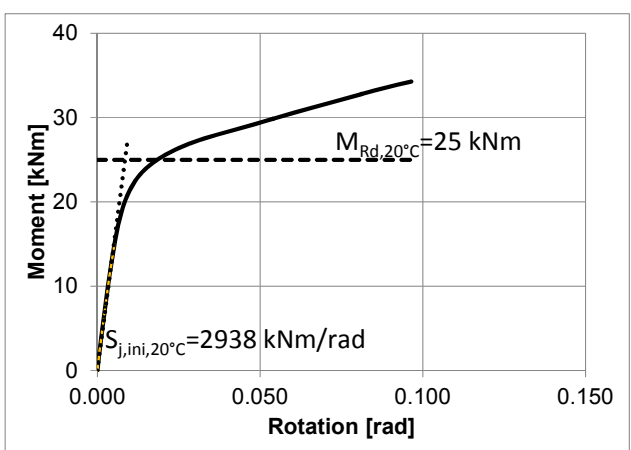

(b)

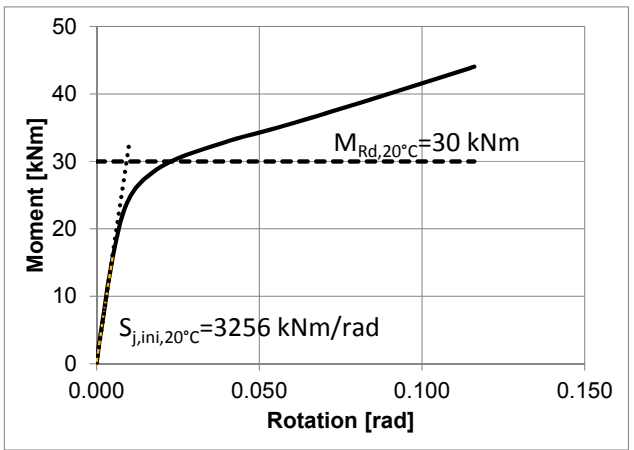

(c)

Figure 10. Moment-vs-rotation Diagram of Reverse Channel Connection

(a) $12 \mathrm{~mm}$ thickness, (b) $8 \mathrm{~mm}$ thickness, (c) $10 \mathrm{~mm}$ thickness

The stiffness and strength of the three different reverse channel connections are summarised below in Table 2.

Table 2. Initial Stiffness and Strength of the Reverse Channel Connections

\begin{tabular}{c|cc}
\hline $\begin{array}{c}\text { Reverse channel thickness } \\
(\mathrm{mm})\end{array}$ & $\begin{array}{c}\text { Initial Stiffness }\left(S_{j, \text {,ini,20 }}{ }^{\circ} \mathrm{C}\right) \\
\mathrm{kNm} / \mathrm{rad}\end{array}$ & $\begin{array}{c}\text { Connection strength } \\
\left(M_{\left.R d, 20^{\circ} \mathrm{C}\right)}\right. \\
\mathrm{kNm}\end{array}$ \\
\hline 12 & 4585 & 40 \\
10 & 3256 & 30 \\
8 & 2938 & 25 \\
\hline
\end{tabular}

\subsection{Material model}

The material models used in the FE-models were based on the coupon tests conducted on specimens from the different structural components, also done at the University of Coimbra. Specimens from all components were tested at room temperature only, except the ones from channel component, which was also tested at elevated temperatures. The results from these coupon tests are summarized in Table 3 [15]. 
Table 3. Mechanical Properties of Steel from Coupon tests [15]

\begin{tabular}{c|cccc}
\hline Structural & Temperature & $\begin{array}{c}\text { Nominal yield } \\
\text { strength }(M P a)\end{array}$ & \multicolumn{2}{c}{ Test result } \\
\cline { 4 - 5 } & $\left({ }^{\circ} \mathrm{C}\right)$ & & $\begin{array}{c}\text { Yield strength } \\
(\mathrm{MPa})\end{array}$ & $\begin{array}{c}\text { Ultimate } \\
\text { strength }(\mathrm{MPa})\end{array}$ \\
End-plate & 20 & 275 & 236.7 & 424.7 \\
(S275) & & & & \\
I-Beam (S355) & 20 & 355 & 446 & 562 \\
SHS (S355) & 20 & 355 & 554.7 & 621.3 \\
Reverse & 20 & 355 & 513.3 & 558.7 \\
channel, SHS & 200 & 355 & 489.3 & 515.7 \\
(S355) & 400 & 355 & 447.3 & 473 \\
& 600 & 166.9 & 249.7 & 252.3 \\
& 800 & 39.1 & 119.7 & 124 \\
Mean $\left(20^{\circ} \mathrm{C}\right)$ & & & 437.7 & 541.7 \\
Standard & & & 122.3 & 71.9 \\
Deviation & & & & \\
$\left(20^{\circ} \mathrm{C}\right)$ & & & & \\
\hline
\end{tabular}

The tri-linear stress-strain curve for carbon steel at elevated temperatures from EN 1993-1-2, shown in Figure 11, was used in the FE Models [11]. This stress-strain model does not consider strain hardening; therefore only yield strength values are taken from the coupon tests.

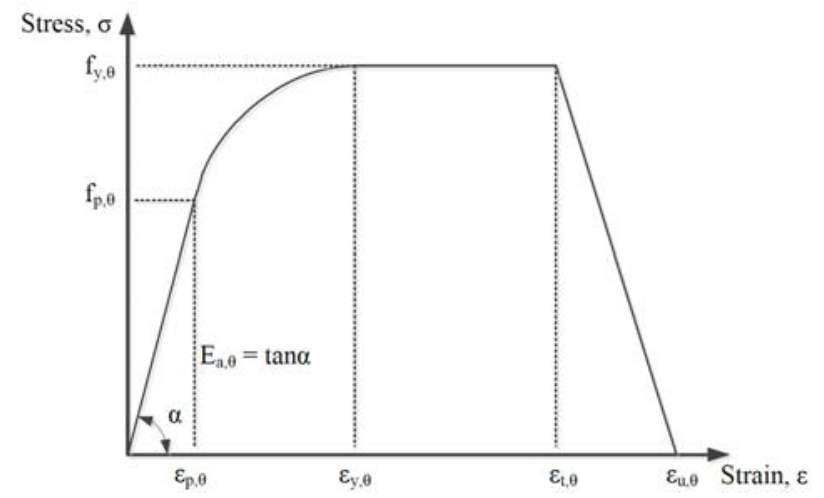

Figure 11. Stress-strain Relationship for Carbon Steel at Elevated Temperatures [12]

The stress-strain curves for the channel component at different temperatures, according to Table 3, are shown in Figure 12. For the other components the reduction factors from EN 1993-1-2 were used for the curves at elevated temperatures. Eq. 3.1 and Eq. 3.2 are used to calculate the true values of the stresses and strains from their nominal values [14].

$\varepsilon_{\text {true }}=\ln \left(1+\varepsilon_{\text {nom }}\right)$

$\sigma_{\text {true }}=\sigma_{\text {nom }}\left(1+\varepsilon_{\text {nom }}\right)$ 


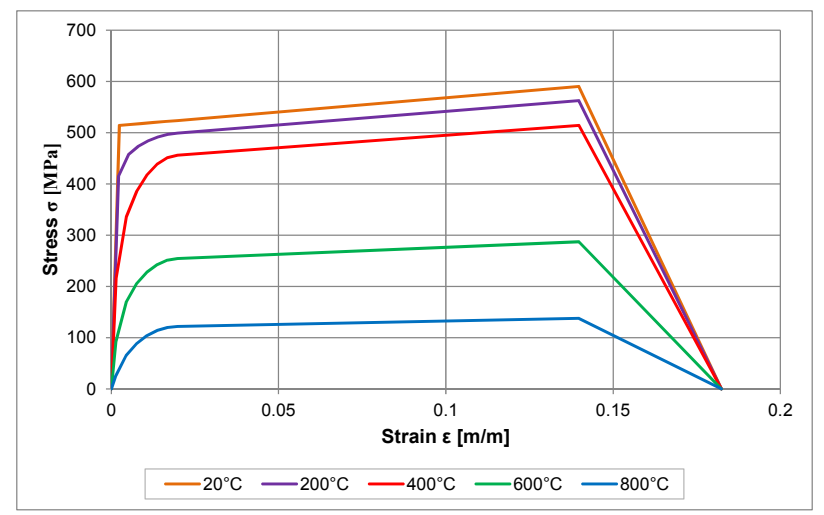

Figure 12. Stress-strain Curve at Elevated Temperatures from Coupon Tests

Nominal material properties of bolt grade 10.9 from EN 1993-1-1 were used [17]. The stress-strain model for the bolts was based on the analytical model proposed in the European project COSSFIRE [18]. Figure 13 shows this model at different temperatures for the bolt grade 10.9.

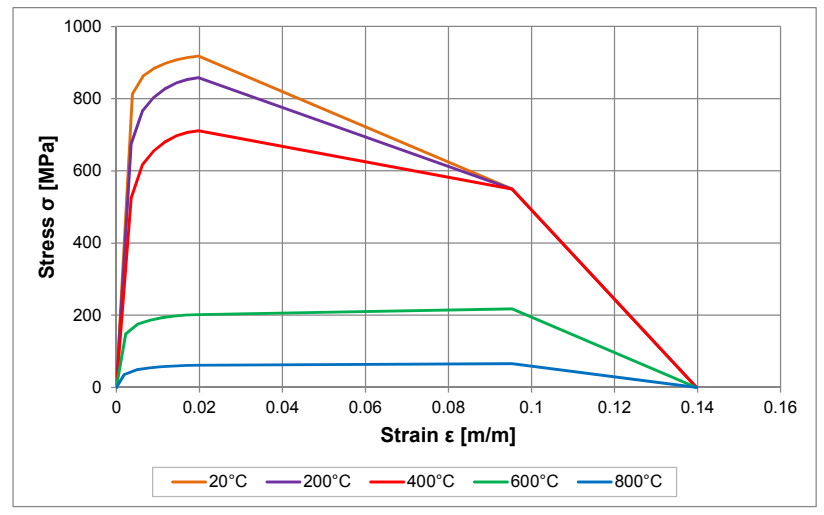

Figure 13. Stress-strain Curve at Elevated Temperatures for Bolt Material

\subsection{Element Type}

The sub-frame has been modelled using 3D solid reduced integration elements C3D8R. The use of first order reduced integration elements can reduce computation time but the drawback for such elements can be 'hourglassing'. However, in Abaqus, first order reduced integration elements possess hourglass controls, which in combination with a fine mesh can solve the problem of 'hourglassing'.

\subsection{Analyses Procedure}

The analysis of the sub-frame model is performed in a series of four 'Static general' steps described below:

Bolt pretensioning: As the first step in the simulation, the bolts are pretensioned in order to initialize the contact interactions and prevent any rigid body motions later in the analysis.

Fixing the bolt length: The second step, is to fix the bolts at their current lengths using Abaqus bolt load option 'fix-current-length'. Bolts are passive entities and not actively force driven; therefore this step ensures this by keeping the bolts at a particular compression distance. 
Load application: A pressure load is applied on the top flange of the beam on an area and at positions corresponding to the tests.

Temperature incrementation: In the last step, thermal loading is applied as increasing temperature in the model as a predefined field according to the temperature-time measurements made in the tests.

\section{VALIDATION OF FE MODEL}

The axial force and midspan deflection obtained from the analysis of the FE models have been compared to the corresponding results from the tests. Figure 14 and Figure 15 show these results for the beam axial force and the midspan deflection respectively.

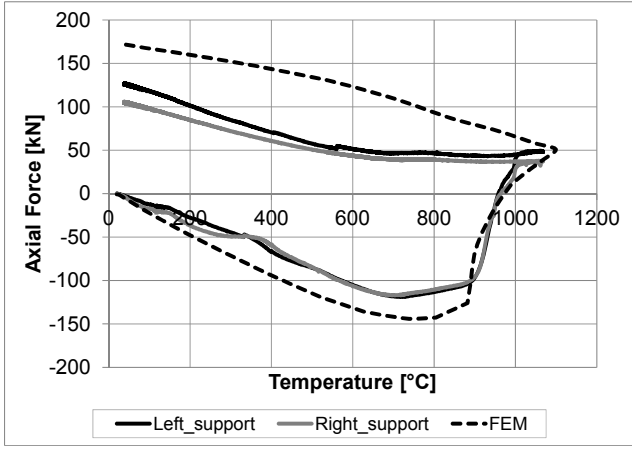

Test No. 1

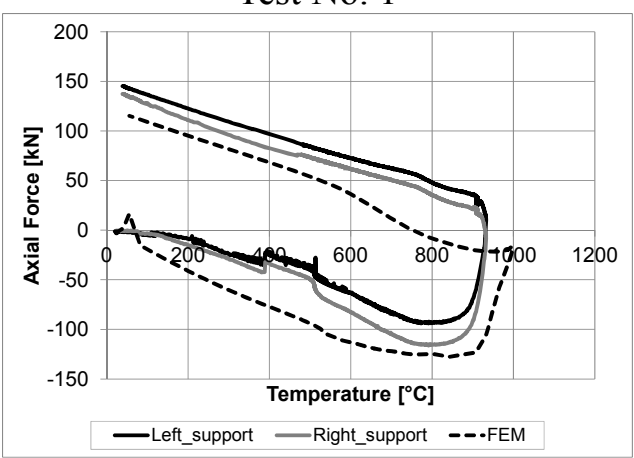

Test No. 3

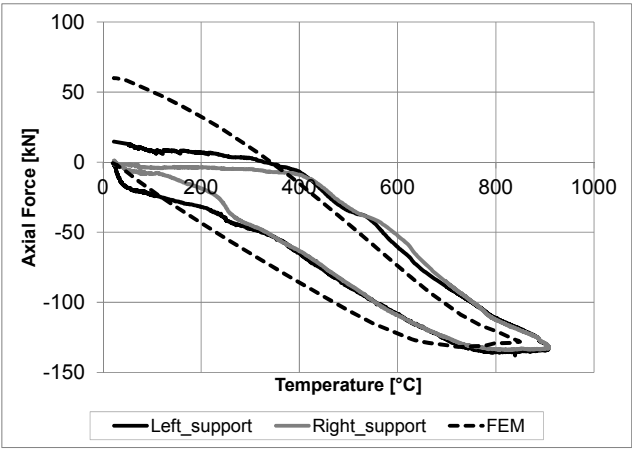

Test No. 2

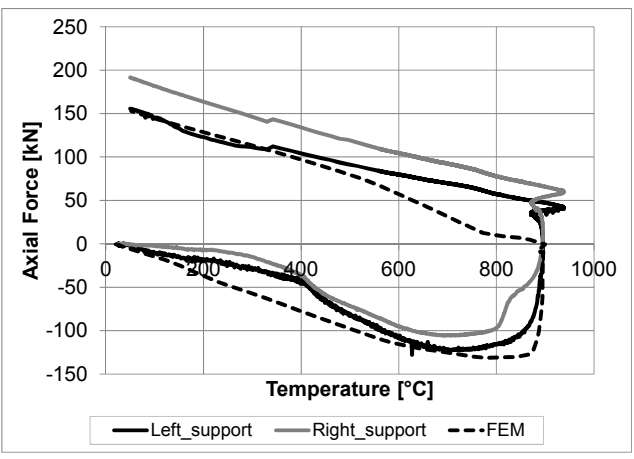

Test No. 4

Figure 14. Axial force-vs-temperature from Tests and Finite Element Modelling

Figure 14 shows that the variation of axial force in the FE models is very close to the test results. However, Figure 15 shows relatively sharp difference between the FE models and test results. Two reasons could be attributed to this difference; firstly FE models are generally expected to give stiff response. Second could be the uncertainty of the material strength at elevated temperature compared to Eurocode. Nevertheless, the results are close enough to warrant the reliability of the FE models for this study. 


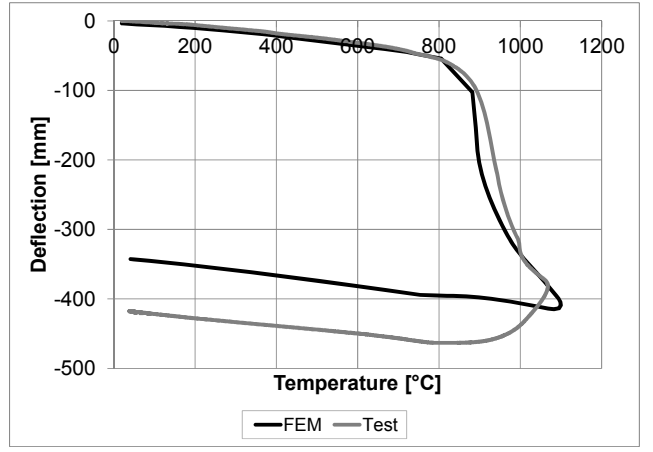

Test No. 1

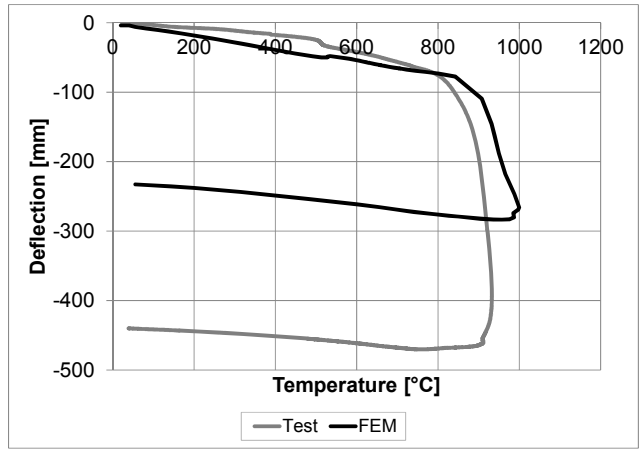

Test No. 3

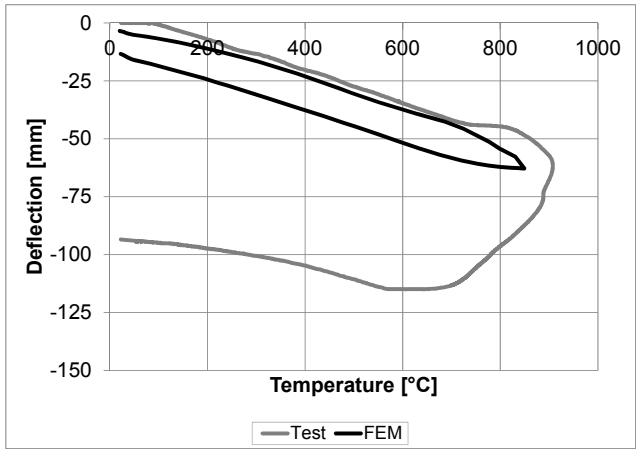

Test No. 2

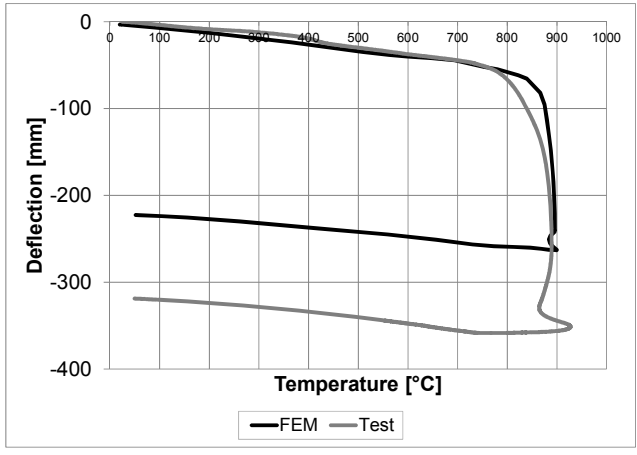

Test No. 4

Figure 15. Midspan deflection-vs-temperature from Tests and Finite Element Modelling

\section{VALIDATION AND DISCUSSION OF ANALYTICAL METHOD}

The validated FE models have been further used here to verify the proposed analytical procedure. Two different load levels (fraction of the ambient temperature design resistance) for each of the three channel thicknesses of the connection are used for comparison between FE model and analytical procedure. Table 4 presents a list of the models used here.

Table 4. FE-models used for the Verification of the Analytical Procedure

\begin{tabular}{c|ccc}
\hline No. & Beam profile & Reverse channel thickness $(\mathrm{mm})$ & Load level \\
& & & \\
\hline 1. & IPE 300 & 8 & 0.4 \\
2. & IPE 300 & 8 & 0.6 \\
3. & IPE 300 & 10 & 0.4 \\
4. & IPE 300 & 10 & 0.6 \\
5. & IPE 300 & 12 & 0.4 \\
6. & IPE 300 & 12 & 0.6 \\
\hline
\end{tabular}

Figure 16 and Figure 17 show these comparisons for axial force and midspan deflection, respectively two support conditions, i.e. simply supported and semi-rigid (reverse channel). 


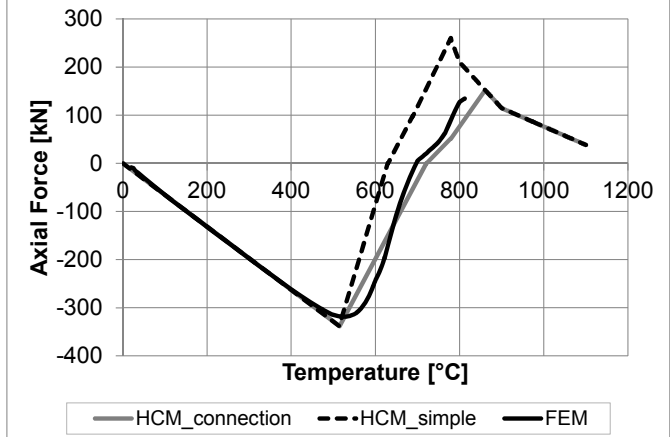

Model 1

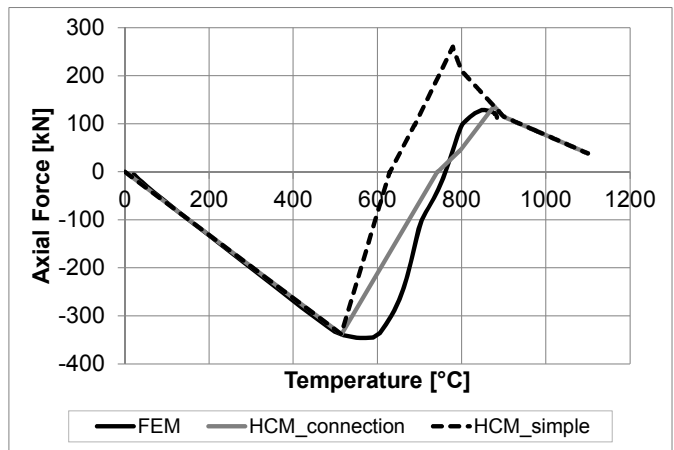

Model 3

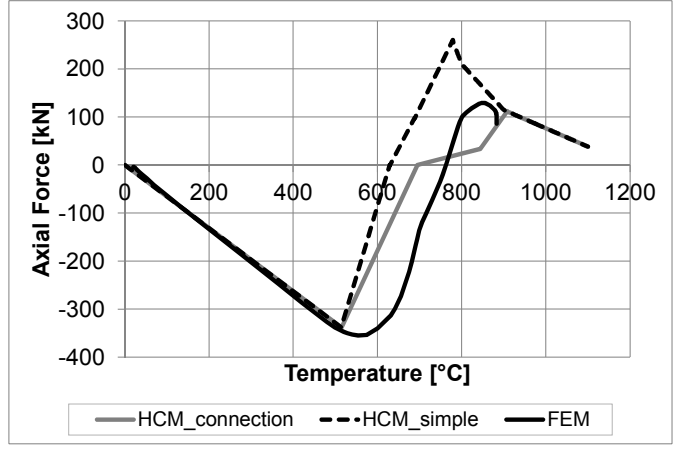

Model 5

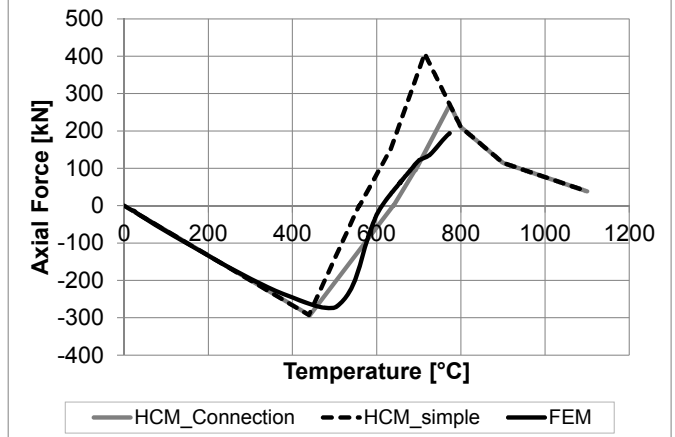

Model 2

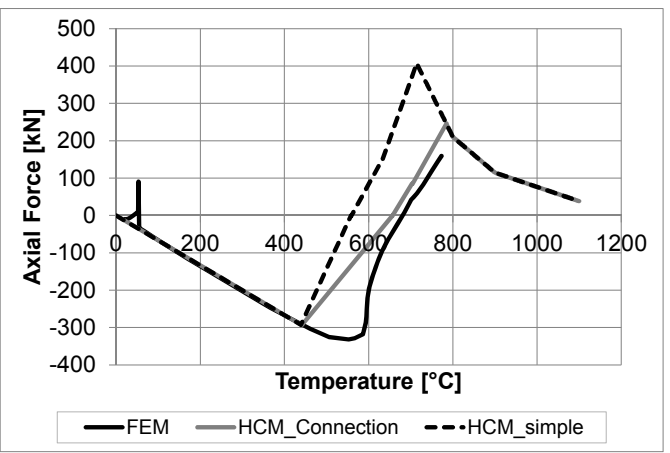

Model 4

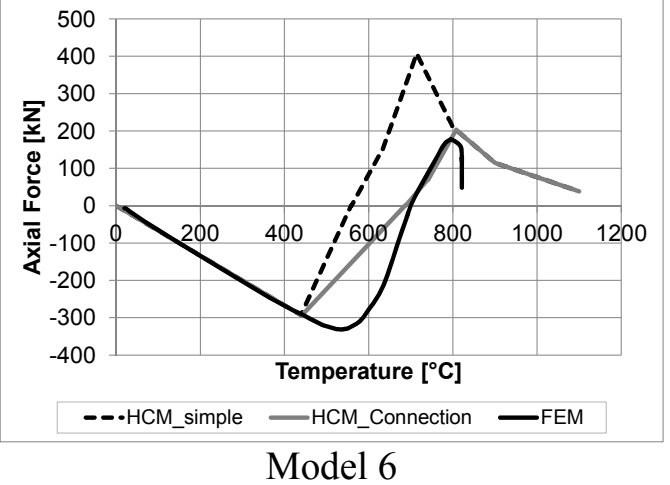

Figure 16. Variation of Axial Force in Steel Beam with Increasing Temperature

Comparison between the FE models and the tests and later the analytical procedure gives some important insights. Figure 14 shows similar response between FE models and tests of compression in the initial phase and tensile catenary action in the later phase of heating. Test 2 is an exception where the beam has not been heated until the catenary phase and was cooled off earlier. All tests show the beam to be in tension during the cooling phase. Test 1 shows the highest tensile force in the catenary phase due to being heated the most.

Test 1 and Test 2 shows the biggest difference from the FE model in terms of the tensile force after cooling. Difference in the column stiffness could be the reason for this as the column was not heated in the FE model. The difference in deflection between the FE models and tests could be due to the difference in real material properties at elevated temperatures and the ones proposed by Eurocode as used in FE models.

The comparison between the FE models and the analytical procedure, according to Figure 16, shows the significance of using the connection moment in the calculation procedure. Table 5 gives a summary of the results from the comparison. 


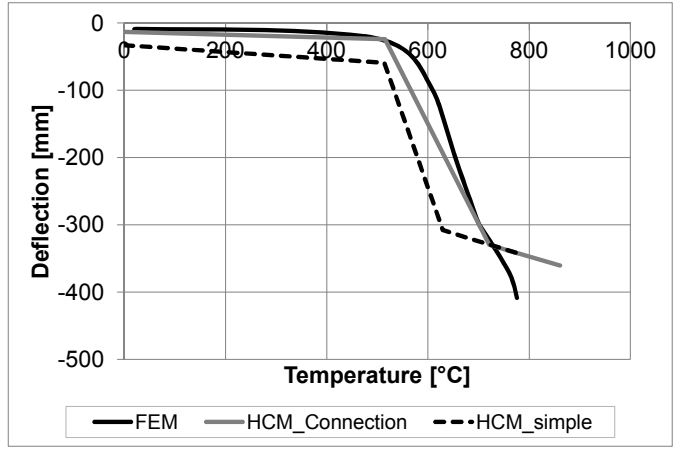

Model 1

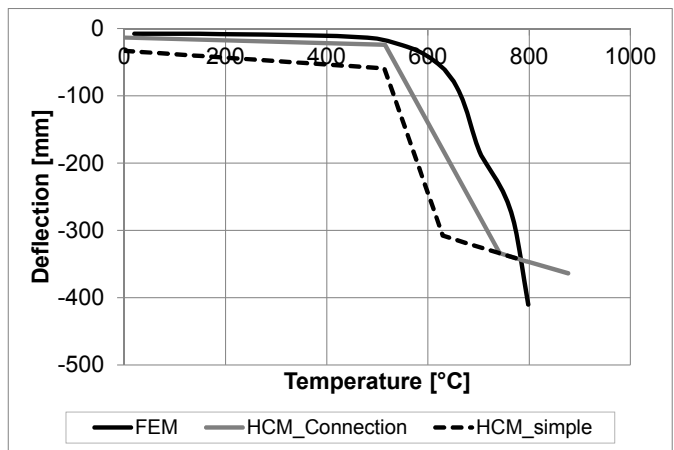

Model 3

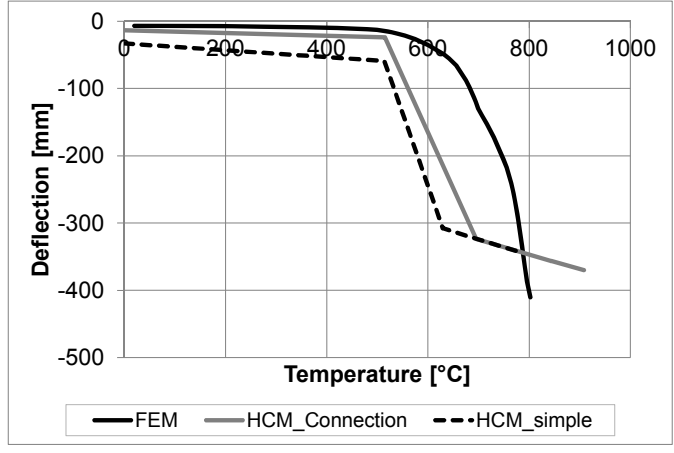

Model 5

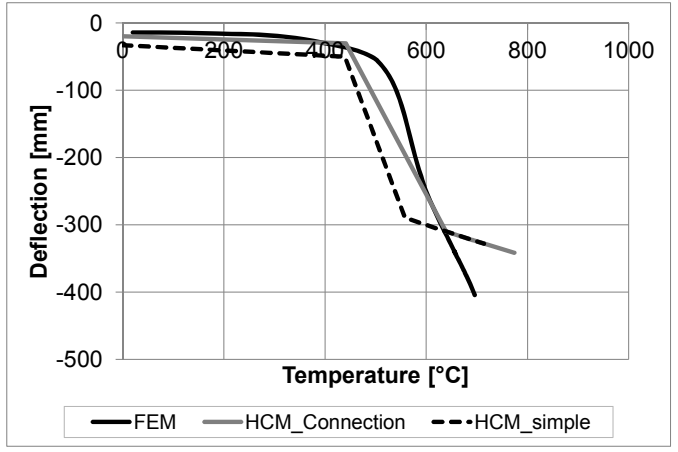

Model 2

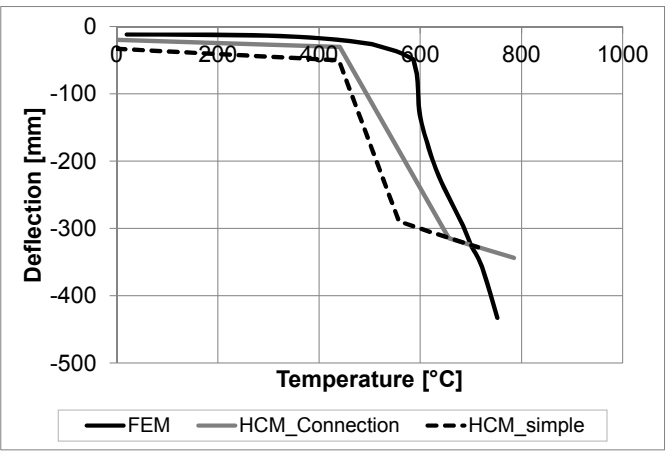

Model 4

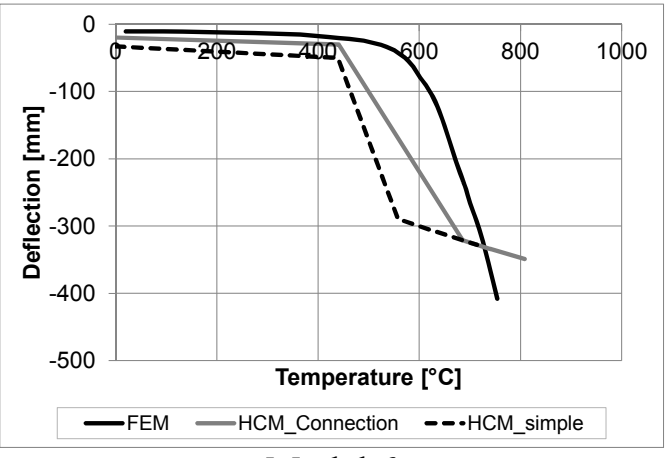

Model 6

Figure 17. Variation of Midspan Deflection in Steel Beam with Increasing Temperature

Table 5. Results from FE-models and Hand Calculation Procedures

\begin{tabular}{|c|c|c|c|c|c|c|c|c|c|c|c|c|c|}
\hline \multirow[t]{2}{*}{ No. } & \multicolumn{3}{|c|}{$\begin{array}{l}\text { Maximum compressive } \\
\text { force }(k N)\end{array}$} & \multicolumn{5}{|c|}{ Temperature (zero axial force) $\left[{ }^{\circ} \mathrm{C}\right]$} & \multicolumn{5}{|c|}{ Maximum tensile force $(\mathrm{kN})$} \\
\hline & FEM & $\mathrm{HCM}$ & Diff. $\%$ & FEM & $\begin{array}{c}\text { HCM } \\
\text { (simple } \\
\text { supports) }\end{array}$ & Diff. $\%$ & $\begin{array}{c}\text { HCM } \\
\text { (Connection } \\
\text { moment) }\end{array}$ & Diff. \% & FEM & $\begin{array}{c}\text { HCM } \\
\text { (simple } \\
\text { supports) }\end{array}$ & Diff. $\%$ & $\begin{array}{c}\text { HCM } \\
\text { (Connection } \\
\text { moment) }\end{array}$ & Diff. $\%$ \\
\hline Model-1 & 318 & 338 & 6.29 & 697 & 629 & 9.7 & 721 & 3.43 & 135 & 260 & 93.4 & 152 & 13.2 \\
\hline Model-2 & 274 & 294 & 7.23 & 616 & 558 & 9.35 & 639 & 3.83 & 194 & 408 & 110 & 267 & 39 \\
\hline Model-3 & 346 & 338 & 2.33 & 763 & 629 & 17.6 & 742 & 2.8 & 129 & 260 & 102 & 137 & 6.38 \\
\hline Model-4 & 332 & 294 & 11.46 & 684 & 558 & 18.5 & 657 & 4.0 & 159 & 408 & 156 & 247 & 55 \\
\hline Model-5 & 355 & 338 & 4.65 & 764 & 629 & 17.7 & 695 & 9.0 & 129 & 260 & 101 & 112 & 13.2 \\
\hline Model-6 & 331 & 294 & 11.33 & 700 & 558 & 20.3 & 686 & 2.0 & 178 & 408 & 129 & 203 & 14.4 \\
\hline
\end{tabular}

From the results in Table 5, it can be seen that consideration of the connection reduces the difference between the results from FE models and the analytical. The simply supported beam assumption in the analytical procedure gives conservative results for point (2) and point (4). 
Similarly the midspan deflection from the analytical procedure with connection moment included (Figure 17) shows convergence towards the numerical results, whereas the model based on simple support assumption is diverging with increasing temperature. A detailed design example is provided in the ANNEX for a given beam and column dimensions.

\section{DISCUSSION AND CONCLUSIONS}

The method presented in this study is based on the assumption that the temperature is uniform across the beam cross section depth. However, in reality the temperature of the top flange can be lower than the web and bottom flange due to its proximity to the concrete slab. This would cause the beam to have a higher resistance at elevated temperature than shown here and could be incorporated into future extension of this approach. The restrained thermal expansion of the beam will induce second order bending moment in the compressive phase of the beam, which has not been taken into account here based on small deflection assumption; however, this can also be introduced as a further extension to this proposed approach in future work.

Main conclusions derived from the study presented here are as follows:

- In the absence of a component method procedure for the connection type considered in this study, a numerical approach was adopted which gave a satisfactory estimation of the connection strength. This is born out of the fact that the analytical procedure has been significantly accurate with these estimated connection strength used as inputs.

- At elevated temperatures material properties such as it strength and stiffness degrade; this degradation has certain uncertainty associated with them, but despite this fact the FE models have been able to simulate the behaviour of the tests satisfactorily. .

- The connection moment resistance at elevated temperatures, though not very significantly high, can contribute towards significantly increasing the conventional limiting temperature (defined by the point of zero axial force in the beam). This increase in temperature can range from $60{ }^{\circ} \mathrm{C}$ to $120{ }^{\circ} \mathrm{C}$, from its value without it.

- The semi-rigid connection contributes towards reducing the difference between the maximum catenary force from the analytical procedure and the FE model results. The difference is $24 \%$ for the procedure with semi-rigid connection whereas $115 \%$ for the procedure without semi-rigid connections.

- The deflection profile obtained from the analytical procedure is also much closer to the FE model results when considering the contribution of the semi-rigid connection. This indicates that the connection strength is significant despite the fact that the connection type considered here in this study is not a moment type connection.

\section{ACKNOWLEDGMENT}

The authors acknowledge the funding from the European Community's Research Fund for Coal and Steel (RFCS) under grant agreement $n^{\circ}$ RFSR-CT-2009-00021, which leads to the research work presented here. 


\section{REFERENCES}

[1] McAllister, T.P., "Structural Fire Response and Probable Collapse Sequence of World Trade Center Building 7, Federal Building and Fire Safety Investigation of the World Trade Center Disaster (NIST-NCSTAR 1-9) VOUMES 1 and 2", National Institute of Standards and Technology, NIST, 2008, pp. 1129-1140.

[2] Kirby, B.R., "Large Scale Fire Tests: The British Steel European Collaborative Research Programme on the BRE-8", Fire Safety Science - Proceedings of the Fifth International Symposium, 1997, pp. 1129-1140.

[3] Liu, T.C., Fahad, M., Davies, J., "Experimental Investigation of Behaviour of Axially Restrained Steel Beams in Fire”, Journal of Constructional Steel Research , 2002, Vol. 58, No. 9, pp. 1211-1230.

[4] Yin, Y.Z. and Wang, Y.C., "A Numerical Study of Large Deflection Behaviour of Restrained Steel Beams at Elevated Temperatures", Journal of Constructional Steel Research, 2004, Vol. 60, No. 7, pp. 1029-1047.

[5] Yin, Y.Z. and Wang, Y.C., "Analysis of Catenary Action in Steel Beams using a Simplified Hand Calculation Method, Part 1: Theory and Validation for Uniform Temperature Distribution", Journal of Constructional Steel Research, 2005, Vol. 61, No. 2, pp. 183-211.

[6] Yin, Y.Z. and Wang, Y.C., "Analysis of Catenary Action in Steel Beams using a Simplified Hand Calculation Method, Part 2: Validation for Non-uniform Temperature Distribution," Journal of Constructional Steel Research, 2005, Vol. 61, No. 2, pp. 213-234.

[7] Li, G.Q. and Guo, S.X., "Experiment on Restrained Steel Beams subjected to Heating and Cooling", Journal of Constructional Steel Research , 2008, Vol. 64, No. 3, pp. 268-274.

[8] Santiago, A., da Silva, L.S., Real, P.V. and Veljkovic, M., "Numerical Study of a Steel Sub-frame in Fire", Computers and Structures , 2008, Vol. 86, No. 15, pp. 1619-1632.

[9] Gillie, M., "Analysis of Heated Structures: Nature and Modelling Benchmarks", Fire Safety Journal , 2009, vol. 44, no. 5, pp. 673-680.

[10] Wang, Y.C., Burgess, I., Wald, F. and Gillie, M., "Performance Based Fire Engineerig of Structures", CRC Press , 2012, $1^{\text {st }}$ Edition, pp. 394.

[11] EN 1993-1-2, Eurocode 3: Design of Steel Structures Part 1-2: General Rules-Structural Fire Design, Brussels: European Committee for Standardization, 2004.

[12] Usmani, A.S., Rotter, J.M., Lamont, S., Sanad, A.M. and Gillie, M., "Fundamental Principles of Structural Behaviour under Thermal Effects”, Fire Safety Journal, 2001, Vol. 36, No. 8, pp. 721-744.

[13] Dwaikat, M.M.S. and Kodur, V.K.R., “A Performance based Methodolgy for Fire Design of Restrained Steel Beams”, Journal of Constructional Steel Research , 2011, Vol. 67, No. 3, pp. 510-524.

[14] Abaqus, Abaqus Users' Manual v6.12, Simulia, RI, USA, 2012

[15] da Silva, L.S., Santiago, A., Lopes, F., Veljkovic, M., Heistermann, T., Iqbal, N., Wald, F., Jana, T., Davison, B., Burgess, I., Huang, S-S., Dong, G., Wang, Y., Mandal, P., Hu, Y., Jafarian, M., Koutlas, G. (2013). COMPFIRE: Design of Composite Joints for Improved Fire Robustness. Final Report No. 4, Research Fund for Coal and Steel, Grant agreement n. ${ }^{\circ}$ RFSR-CT-2009-00021, European Commission, Brussels.

[16] Lopes, F., Santiago, A., da Silva, L.S., Iqbal, N., Veljkovic, M and da Silva, J.G.S., "Sub-frames with Reverse Channel Connections to CFT Composite Columns-experimental Evaluations", Advanced Steel Construction , 2015, Vol. 11, No. 1, pp. 110-125.

[17] EN 1993-1-1, Eurocode 3: Design of Steel Structures Part 1-1: General Rules and Rules for Buildings, Brussels: European Committee for Standardization, 2005.

[18] Zhao, B., Roosefid, M. (2009). COSSFIRE: Connections of Steel and Composite Structures under Natural Fire Conditions. Final Report No. 6, Research Fund for Coal and Steel, Grant Agreement n. ${ }^{\circ}$ RFSR-CT-2006-00028, European Commission, Brussels. 


\section{ANNEX}

\section{Design Example:}

Determine the maximum axial compressive force and the maximum axial tensile force generated in a $6 \mathrm{~m}$ unprotected steel beam exposed to a standard fire (ISO 834). The cross sectional profile of the beam is an IPE 330 made of steel grade S355 and it is connected at its ends to supporting HD $360 \times 134$ profile columns through semi-rigid reverse channel connections. The floor height is 3.5 meters. The utilization factor of the beam is 0.4 .

\section{$\underline{\text { Step 1: Cross section classification }}$}

For fire design situation: $\varepsilon_{\theta}=0.85 \sqrt{235 / f_{y}}=0.85 \sqrt{235 / 355}=0.692$

[EN 1993-1-2]

Top flange [outstand compression element]

Width to thickness ratio:

$9 \varepsilon_{\theta}<C_{f} / t_{f}=5.06<10 \varepsilon_{\theta} \Rightarrow$ class $=1$ [EN 1993-1-1: table 5.2]

Web [internal compression element]

Width to thickness ratio:

$42 \varepsilon_{\theta}>C_{w} / t_{w}=36.13 \Rightarrow$ class $=4[$ EN 1993-1-1: table 5.2]

Step 2: Effective cross-section properties:

Stress distribution ratio (web): $\psi=1$

Plate buckling factor (web): $\quad k_{\sigma}=4.0$

Plate slenderness (web): $\lambda_{p}=\left[c_{w} / t_{w}\right] /\left[28.4 \cdot \varepsilon \cdot \sqrt{k_{\sigma}}\right]=0.782$

[EN 1993-1-5: section 4.4]

Reduction factor: $\quad \rho=\left[\lambda_{p}-0.055(3+\psi] / \lambda_{p}^{2}=0.919\right.$

[EN 1993-1-5: section 4.4]

Effective web width: $\quad h_{w, e f f}=\rho \times h_{w}=249.07 \mathrm{~mm}$

Area of effective cross section: $A_{\text {eff }}=6096 \mathrm{~mm}^{2}$

Moment of inertia (strong axis): $I_{\text {eff }}=117693414 \mathrm{~mm}^{4}$

Step 3: Axial support stiffness (columns):

Length of column: $L_{c}=2 \times$ floor height $=7 \mathrm{~m}$

Axial support stiffness: $K_{c}=192 \mathrm{EI} / L_{c}^{3}=48.8 \mathrm{kN} / \mathrm{mm}$ 
Step 4: Maximum compressive force (Point-1):

At temperature $\theta$ :

Axial force in the beam due to restrained thermal expansion:

$$
\mathrm{N}_{\mathrm{Ed}}=\mathrm{EA} \alpha \theta /\left[1+\mathrm{EA} /\left(0.5 \mathrm{~K}_{\mathrm{c}} \mathrm{L}_{\mathrm{b}}\right)\right]
$$

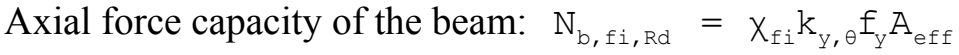

Bending moment resistance at $20^{\circ} \mathrm{C}: \mathrm{M}_{\mathrm{C}, \mathrm{Rd}}=\mathrm{W}_{\mathrm{el}, \mathrm{eff}} \mathrm{f}_{\mathrm{y}} / \mathrm{Y}_{\mathrm{Mfi}}=253 \mathrm{kNm}$

Applied bending moment in fire: $\mathrm{M}_{\mathrm{fi}, \mathrm{ed}}=0.4 \mathrm{M}_{\mathrm{c}, \mathrm{Rd}}=101 \mathrm{kNm}$

Bending moment resistance in fire: $\quad \mathrm{M}_{\mathrm{fi}, \mathrm{Rd}}=\mathrm{W}_{\mathrm{el}, \mathrm{eff}} \mathrm{k}_{\mathrm{y}, \theta} \mathrm{f}_{\mathrm{y}} / \mathrm{Y}_{\mathrm{Mfi}}$

Design resistance for combined bending and compression:

$$
\mathrm{N}_{\mathrm{Ed}} / \mathrm{N}_{\mathrm{b}, \mathrm{fi}, \mathrm{Rd}}+\mathrm{k}_{\mathrm{y}} \mathrm{M}_{\mathrm{fi}, \mathrm{Ed}} / \mathrm{M}_{\mathrm{fi}, \mathrm{Rd}} \leq 1
$$

Where, $\quad \mathrm{k}_{\mathrm{y}}=1-\mu_{\mathrm{y}} \mathrm{N}_{\mathrm{Ed}} / \mathrm{N}_{\mathrm{b}, \mathrm{fi}, \mathrm{Rd}} \leq 3$

And $\quad \mu_{y}=\left(1.2 \beta_{M, y}-3\right) \lambda_{\theta}+0.44 \beta_{M, y}-0.29 \leq 0.8$

[EN 1993-1-2]

Incrementally increasing the temperature until the design resistance for combined bending and compression is reached:

$\theta_{1}=391^{\circ} \mathrm{C}, \mathrm{N}_{1}=605 \mathrm{kN}$ [maximum compressive force]

\section{Step 5: Zero Axial force (Point-2)}

Bending moment capacity of connection $20^{\circ} \mathrm{C}: \mathrm{M}_{\mathrm{conn}}=40 \mathrm{kNm}$

\section{As a first iteration:}

Assuming simple supports: $\quad f_{\mathrm{y}, \theta}=\mathrm{M}_{\mathrm{fi}, \mathrm{Ed}} / \mathrm{W}_{\mathrm{el}, \mathrm{eff}}=142 \mathrm{MPa}$

Reduction factor: $\quad f_{y, \theta}=142 \mathrm{MPa} \Rightarrow \mathrm{k}_{\mathrm{y}, \theta}=\mathrm{f}_{\mathrm{y}, \theta} / \mathrm{f}_{\mathrm{y}}=0.4$

Beam temperature: $\quad \mathrm{k}_{\mathrm{y}, \theta}=0.4 \Rightarrow \theta=629^{\circ} \mathrm{C}$

Connection temperature:

$$
\theta_{\text {conn }}=0.88 \theta(1-0.3 \mathrm{~h} / \mathrm{D})=470^{\circ} \mathrm{C} \text { for } \mathrm{h} / \mathrm{D}=0.5
$$

[EN 1993-1-2]

Reduction factor (connection): $\theta_{\mathrm{conn}}=470^{\circ} \mathrm{C} \Rightarrow \mathrm{k}_{\mathrm{y}, \mathrm{conn}}=0.845$

Connection resistance: $\quad \mathrm{M}_{\mathrm{conn}, \mathrm{fi}}=\mathrm{k}_{\mathrm{y}, \mathrm{conn}} \mathrm{M}_{\mathrm{conn}}=33.8 \mathrm{kNm}$

Considering connection resistance to calculate $\mathrm{f}_{\mathrm{y}, \theta}$

$$
f_{y, \theta}=\left[M_{f i, E d}-2 M_{c o n n, f i}\right] / W_{e l, e f f}
$$

Using $\mathrm{f}_{\mathrm{y}, \theta}$ to perform the next iteration and so on until the reduction factor $\mathrm{k}_{\mathrm{y}, \text { conn }}$ becomes repetitive:

$\mathrm{k}_{\mathrm{y}, \mathrm{conn}}=0.52 \Rightarrow \mathrm{M}_{\mathrm{conn}, \mathrm{fi}}=20.8 \mathrm{kNm} \Rightarrow \mathrm{f}_{\mathrm{y}, \theta}=\left(\mathrm{M}_{\mathrm{fi}, \mathrm{Ed}}-2 \mathrm{M}_{\mathrm{conn}, \mathrm{fi}}\right) / \mathrm{W}_{\mathrm{el}, \mathrm{eff}}=83.7 \mathrm{MPa}$

$f_{y, \theta}=83.7 \mathrm{MPa} \Rightarrow k_{y, \theta}=f_{y, \theta} / f_{y}=0.236$

$\mathrm{k}_{\mathrm{y}, \theta}=0.236 \Rightarrow \theta_{2}=698^{\circ} \mathrm{C}$

Step 6: Tensile force (bending-tension interaction) (Point-3)

In the catenary phase, initially the bending moment resistance is significant, thus interaction with the tensile force is taken into account.

For an incrementally increasing temperature $\theta>\theta_{2}$ :

Residual Moment: $\quad \Delta \mathrm{M}=\mathrm{M}_{\mathrm{fi}, \mathrm{Ed}}-\mathrm{M}_{\mathrm{fi}, \mathrm{Rd}}-2 \mathrm{M}_{\mathrm{conn}, \mathrm{fi}}$ 
Beam deflection: $\delta=\sqrt{[(\mathrm{L}+\alpha \theta \mathrm{L}) / 2)^{2}-(\mathrm{L} / 2)^{2}}$

Axial force: $N_{t}=\Delta M / \delta$

Stop the incrementation when: $\quad \mathrm{N}_{t} \geq \mathrm{N}_{\mathrm{t}, \mathrm{Rd}} \mathrm{OR} \mathrm{N}_{\mathrm{t}} \geq 0.5 \mathrm{~h} \mathrm{t}_{\mathrm{w}} \mathrm{f}_{\mathrm{y}, \theta}$

The values obtained are: $\theta_{3}=778^{\circ} \mathrm{C}, \mathrm{N}_{3}=70 \mathrm{kN}$

\section{Step 7: Maximum tensile force (Point-4)}

For an incrementally increasing temperature $\theta>\theta_{3}$ :

Beam tensile resistance: $N_{t, f i, R d}=A f_{y, \theta} / Y_{M f i}$

Beam deflection: $\delta=\sqrt{[(\mathrm{L}+\alpha \theta \mathrm{L}) / 2)^{2}-(\mathrm{L} / 2)^{2}}$

Residual Moment: $\quad \Delta \mathrm{M}=\mathrm{M}_{\mathrm{fi}, \mathrm{Ed}}-2 \mathrm{M}_{\mathrm{conn}, \mathrm{fi}}$

Stop the incrementation when: $\quad \mathrm{N}_{\mathrm{t}, \mathrm{fi}, \mathrm{Rd}} \times \delta=\Delta \mathrm{M}$

The values obtained are: $\theta_{4}=869^{\circ} \mathrm{C}, \mathrm{N}_{4}=168.7 \mathrm{kN}$ 